\title{
Fast-Growing Gastric Inflammatory Pseudotumor: A Rare Manifestation of Peptic Ulcer Disease
}

Inflammatory pseudotumors (synonymous with inflammatory fibrous polyps) are benign lesions which must be differentiated from other stroma tumors such as leiomyomas or sarcomas. In the stomach, inflammatory pseudotumors are rare.

A 45-year-old woman was admitted because of abdominal pain. At 8 weeks previously, a Helicobacter pylori-positive ulcer in the gastric body had been diagnosed. At 4 weeks after $H$. pylori eradication with Italian triple therapy, the ulceration had healed. However, a mass $1 \mathrm{~cm}$ in size was seen at the same location, and $H$. pylori positivity persisted. Because of increasing epigastric discomfort, another gastroscopy was performed. The tumor was now $4 \mathrm{~cm}$ in diameter and centrally ulcerated (Figure 1). On endoscopic ultrasound, the lesion was hypoechoic and confined to the submucosa. Biopsies showed only normal mucosa. On ultrasound and computed tomography, no evidence of metastatic disease or infiltration of adjacent organs was found. However, because of the rapid growth of the tumor, suggesting malignancy, surgical excision was performed. Histologically, a benign tumor with a maximum diameter of $6 \mathrm{~cm}$ was found (Figure 2). It was located mainly in the submucosal layer, but ex-

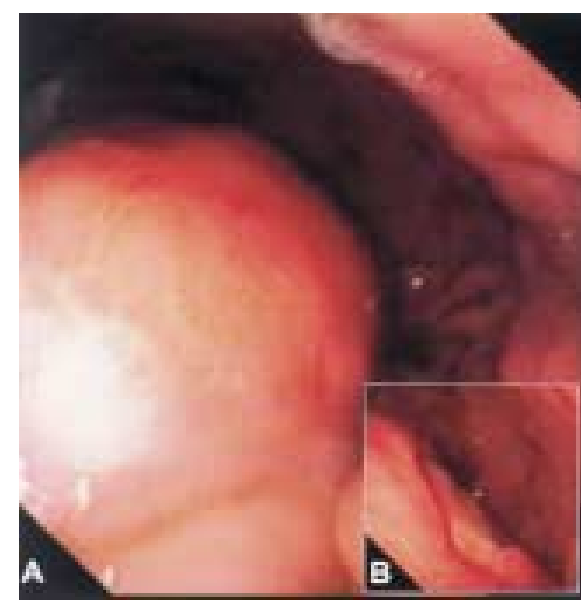

Figure 1 Macroscopic aspect. A A tumor of approximately $4 \mathrm{~cm}$ in diameter in the gastric body. $\mathbf{B}$ The central ulceration tended partially into the muscularis propria.

The size and rapid growth of this gastric inflammatory pseudotumor are very uncommon. Among 5515 gastric polyps studied by Stolte et al. [1], 3.1\% were inflammatory fibroid polyps, none of them being more than $2 \mathrm{~cm}$ in size. For eosinophilic pseudotumors at other locations, fast growth has occasionally been described thus making the discrimination from a malignant tumor difficult [2]. To our knowledge, an association of a gastric pseudotumor with a peptic ulcer as in our patient has not been described so far. Triple therapy led to healing of the ulceration, but was followed by rapid growth of the pseudotumor. An association with the persisting $H$. pylori infection and gastritis has to be assumed.

\section{H. Al-Taie ${ }^{1}$, H. Mörk ${ }^{1}$, M. Jenett ${ }^{2}$,} D. Klein $^{2}$, J. G. Müller ${ }^{3}$, M. Scheurlen ${ }^{1}$

${ }^{1}$ Medizinische Poliklinik, Julius Maximilians University, Würzburg, Germany

${ }^{2}$ Institute for Radiology, Julius Maximilians University, Würzburg, Germany

${ }^{3}$ Institute for Pathology, Julius Maximilians University, Würzburg, Germany

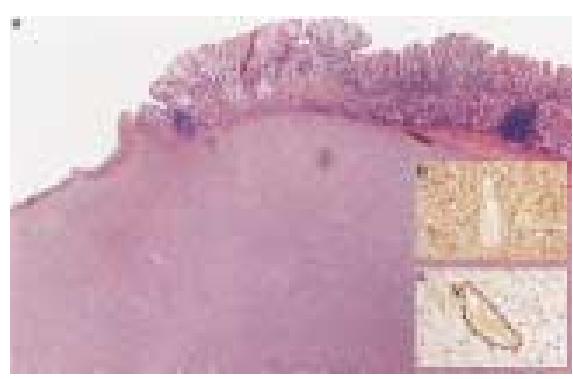

Figure 2 a Inflammatory fibroid polyp with edematous stroma, a mixture of fibroblastic cells, eosinophilic granulocytes and some macrophages, as well as numerous blood vessels. b Immunohistochemistry shows strong expression of CD34 on the fibroblasts. c Expression of muscle-specific actin is weak. There are no mitoses and no atypical cells

\section{References}

${ }^{1}$ Stolte M, Sticht T, Eidt S et al. Frequency, location, and age and sex distribution of various types of gastric polyp. Endoscopy 1994; 26: 659-665

${ }^{2}$ Coffin CM, Watterson J, Priest JR et al. Extrapulmonary inflammatory myofibroblastic tumor (inflammatory pseudotumor). A clinicopathologic and immunohistochernical. study of 84 cases. Am J Surg Pathol 1995; 19: 859-872

\section{Corresponding Author}

\section{O. H. Al-Taie, M.D.}

Medizinische Poliklinik

Julius Maximilians University

Klinikstrasse 6-8

97070 Würzburg

Germany

Phone: + 49-931-2017017

Fax: $\quad$ +49-931-2017068

E-mail: al-taie.medpoli@mail. uni-wuerzburg.de 